\title{
Genetic Impairment of Energy \\ Conservation in Development of Schizophyllum: Efficient Mitochondria in Energy-starved Cells
}

\author{
By R. M. HOFFMAN AND J. R. RAPER \\ Biological Laboratories, Harvard University, Cambridge, Massachusetts 02138, U.S.A.
}

(Received Io July 1973; revised 29 October 1973)

\begin{abstract}
SUMMARY
A mutant-B $\beta$ strain of Schizophyllum commune, in which the B-sequence of sexual morphogenesis is constitutive, utilizes glucose in the production of cellular material with an efficiency of about $9 \%$ of that of wild-type mycelium. The production of ATP by mitochondria isolated from the mutant is equal to that of mitochondria of normal mycelium, however, and mitochondrial ATPase activity appears the same from mycelia of the two types. Other comparative studies show the mutant to achieve approximately the same yield on ethanol and glucose, whereas wild type grows considerably less on ethanol. The mutant is much more sensitive than wild type to temperature and to inhibition by Krebs-cycle intermediaries. Both mutant and wild type are sensitive to the phosphorylation-inhibiting agent, DCCD. The over-all effect is a partial uncoupling of energy-conserving from energy-yielding processes. It was not possible to determine if the agents responsible for uncoupling were solely mitochondrial or cytoplasmic.
\end{abstract}

\section{INTRODUCTION}

Genetic obstruction of the process of energy conservation has been intensely sought in various organisms. Previous studies on intact mycelia of Schizophyllum have shown that a malfunction of energy metabolism is associated with a genetically regulated phase of sexual development known as the B-sequence (Hoffman \& Raper, 197I). The B-sequence can be 'turned on' either by heteroallelism for a $B$ factor gene in a heterokaryon or by a particular mutation of a $B$ gene that results in a constitutively operating B-sequence in the homokaryon (Raper \& Raper, 1973). A wild-type homokaryon carries single alleles of the $B$ genes, and the B-sequence is normally inoperative. The two $B$ genes are nuclear and comprise one of two incompatibility factors that regulate the entire process of sexual morphogenesis (Raper, I966). Both the mutant homokaryon and the heterokaryon heteroallelic for $B$ have greatly reduced growth and altered morphology as compared to the wild-type homokaryon. The poor growth of this phenotype was shown in vivo to be due to a partial uncoupling between energy-yielding and energy-conserving processes (Hoffman \& Raper, 197I). Further experiments with the $B$-mutant strain have shown that the respiratory response of isolated mitochondria to ADP is only one-half that of the wild type (Hoffman \& Raper, 1972). In this report, we quantify for the $B$-mutant strain the degree of uncoupling in the intact organism and show that mitochondria isolated from the mutant strain can make normal amounts of ATP. 


\section{METHODS}

Organism. Two homokaryotic strains of Schizophyllum commune have been used: one, in which the B-sequence is not operative, ' $B$-off', has a wild-type $B$ factor, $B \alpha_{3}-\beta_{2}$; the other, with an operative B-sequence, ' $B$-on', carries a mutation in the $B \beta$ gene, $B \alpha I-\beta 2(I)$. Except for these genes, the two strains were made isogenic by backcrossing the mutant strain to the wild for ten generations (Wang \& Raper, 1969).

Medium. The medium for growth was synthetic (Miles, Lund \& Raper, I956) plus microelements (Hutner, Provasoli, Schatz \& Haskins, 1950) and $2 \%$ glucose except in the molar growth experiments.

Molar growth yields. Mycelia were grown in $50 \mathrm{ml}$ minimal medium in $250 \mathrm{ml}$ Erlenmeyer flasks and incubated at $30{ }^{\circ} \mathrm{C}$ on a reciprocating shaker. Dry weights were obtained by harvesting mycelia on tared filter papers and drying for $24 \mathrm{~h}$ at $105{ }^{\circ} \mathrm{C}$ before weighing. Growth curves based on daily determinations were established for each concentration of glucose, and the maximal weights achieved were plotted against concentration. Maximal weights plotted out as linear functions of glucose concentration, and the slopes of the curves were utilized to calculate molar growth yields. No viscous material was present at the low concentrations of glucose used.

$P / O$ ratios. Mitochondria were obtained as reported previously (Hoffman \& Raper, 1972). $\mathrm{P} / \mathrm{O}$ ratios were determined in $3 \mathrm{ml}$ reaction medium at $30{ }^{\circ} \mathrm{C}$ by measuring oxygen uptake in a Clark-type oxygen electrode in the presence of ${ }^{32} \mathrm{P}_{i}$ with a glucose-hexokinase trap for ATP. The $3 \mathrm{ml}$ reaction medium contained $0.3 \mathrm{M}$-mannitol, Io mM-potassium phosphate buffer, $8 \times 10^{-4} \mathrm{M}$-ADP, $17 \mathrm{~mm}$-glucose, $6 \mathrm{mg}$ hexokinase (from yeast; Sigma), $10^{-2}$ to $5 \times \mathrm{IO}^{-6} \mathrm{M}$-substrate, and approximately $10^{6}$ c.p.m. ${ }^{32} \mathrm{P}_{i}$ (Ohnishi, Kawaguchi \& Hagihara, 1966). Organic ${ }^{32}$ phosphate was determined by extracting away the unreacted ${ }^{32} \mathrm{P}_{i}$ (Nielsen \& Lehninger, I955); I $\mathrm{ml}$ of the aqueous phase containing the organic ${ }^{32}$ phosphate was added to I4 ml Aquasol and counted in a Beckman scintillation counter. Blanks containing the complete system except for mitochondria were always run simultaneously.

$\mathrm{Mg}^{++}$stimulated ATPase activity. Mitochondria were obtained as previously, but bovine serum albumin and cysteine were omitted from the buffer in which the mycelia were disrupted, and the mitochondrial-washing step was eliminated. The reaction was run at $30{ }^{\circ} \mathrm{C}$ for $10 \mathrm{~min}$ in I ml $0.9 \mathrm{~mm}-\mathrm{ATP}$, I $\mathrm{mM}^{-\mathrm{MgSO}_{4}}, 83 \mathrm{~mm}$-sodium acetate, $83 \mathrm{~mm}$-glycine, 83 mm-tris, adjusted to the indicated pH values (Schatz, Penefsky \& Racker, 1967). The reaction was initiated by the addition of 32 to $42 \mu \mathrm{g}$ enzyme. Inorganic phosphate was determined by the method of Ames (I966). The reaction was terminated by pipetting $0.3 \mathrm{ml}$ of the reaction mixture into $0.7 \mathrm{ml}$ Ames assay mix $+0.3 \mathrm{ml} 5 \%$ trichloroacetic acid. Two controls were always run: one without substrate, and one without mitochondria.

Other measurements of growth. Measurements of growth were made as for molar growth yields or by measuring colony diameters.

\section{RESULTS}

\section{Molar growth yields}

Calculations for the wild type gave $94.8 \mathrm{~g}$ dry $\mathrm{wt} / \mathrm{mol}$ glucose. The Elsden constant (Bauchop \& Elsden, 1960) of $10.5 \mathrm{~g}$ dry wt/mol ATP from an energy source when divided into the $94.8 \mathrm{~g}$ dry wt obtained from wild-type growth indicates a yield of $9 \mathrm{~mol}$ ATP $/ \mathrm{mol}$ glucose as sole carbon and energy source. It has previously been demonstrated (Hoffman \& Raper, 197I) that when glucose is the sole carbon and energy source for wild-type Schizophyllum, one-quarter of the glucose is used for energy. Therefore, because 9 mol ATP are 
Table I. P/O ratios of mitochondria isolated from B-off wild-type and $B$-on mutant strains of Schizophyllum

\begin{tabular}{|c|c|c|}
\hline & \multicolumn{2}{|c|}{ Wild type } \\
\hline $\begin{array}{l}\text { abstrate } \\
\text { (M) }\end{array}$ & $\begin{array}{c}\mathbf{P}_{\boldsymbol{i}} \\
(\mathrm{nmol} / \\
\mathrm{min} / \mathrm{mg} \\
\text { protein) }\end{array}$ & $\begin{array}{c}\mathrm{O} \\
\text { (nanoatoms/ } \\
\text { min } / \mathrm{mg} \\
\text { protein) }\end{array}$ \\
\hline
\end{tabular}

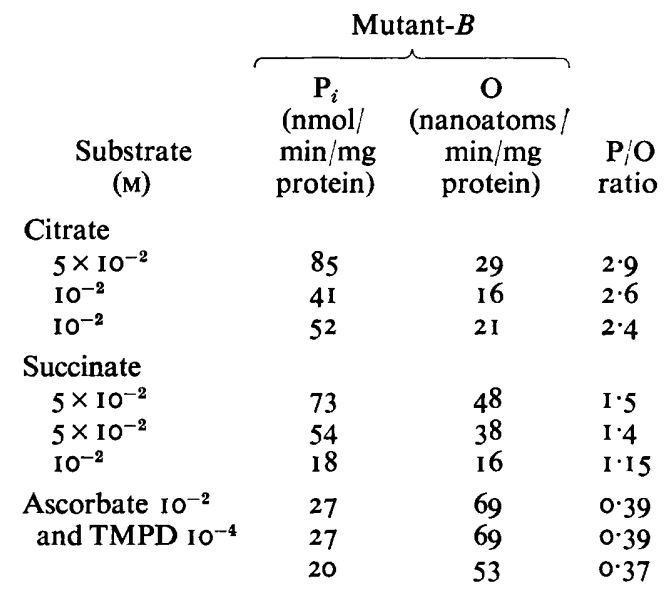

formed from $\frac{1}{4}$ mol glucose as an energy source, the burning of I mol would yield $36 \mathrm{~mol}$ ATP, approximately the theoretical figure. This agreement of the actual finding to the theoretical value seems to justify the use of 10.5 as the Elsden constant for Schizophyllum, although some variations have been reported in other organisms (Stouthamer, 1969).

Similar calculations for the $B$-on mutant strain show $22.5 \mathrm{~g}$ dry $\mathrm{wt} / \mathrm{mol}$ glucose. This number divided by the Elsden constant gives a figure of $2 \cdot \mathrm{I} \mathrm{mol} \mathrm{ATP} / \mathrm{mol}$ glucose as sole carbon and energy source. The mutant, however, burns 0.62 of the glucose present as a sole carbon and energy source (Hoffman \& Raper, I97I); if the mutant were to burn I mol glucose, it would obtain $3.4 \mathrm{~mol}$ ATP. The $B$-on mutant is thus only approximately $9.4 \%$ as efficient as the $B$-off wild type.

\section{$P / O$ ratios}

$\mathrm{P} / \mathrm{O}$ ratios were measured with citrate, succinate, and ascorbate- $N, N, N,{ }^{\prime} N$-tetramethyl$p$-phenylenediamine as substrates, which give theoretical maximal values of 3,2 , and I respectively. Mitochondria of both $B$-on and $B$-off strains gave values $>2$, $>1$, and $>0.35$ for the respective substrates (Table I). These to our knowledge are the first coupled mitochondria isolated from a basidiomycetous fungus. In view of the marked inefficiency of the $B$-on mutant cell, these values were quite surprising. Previous experiments have shown, however, that the respiratory response of the mitochondria of the mutant is only half that of normal type, and in vivo these mitochondria may be 'loosely coupled' in the sense of Ernster (Ernster \& Luft, 1963).

\section{Mitochondrial ATPase activities}

Because the $\mathrm{P} / \mathrm{O}$ ratios were measured in the presence of an ATP-trapping system, it was thought that any possible elevated ATPase activity in the mutant would be masked. Measurements of mitochondrial $\mathrm{Mg}^{++}$ATPase activity versus $\mathrm{pH}$ seem to indicate similar activity profiles of mutant and wild type (Fig. I). The curves follow each other quite closely to $\mathrm{pH}$ 9. These experiments, however, do not rule out the possibility of a cytoplasmic ATPase present in the mutant. Attempts to demonstrate cytoplasmic ATPase by release of $\mathbf{P}_{i}$ were unsuccessful. 


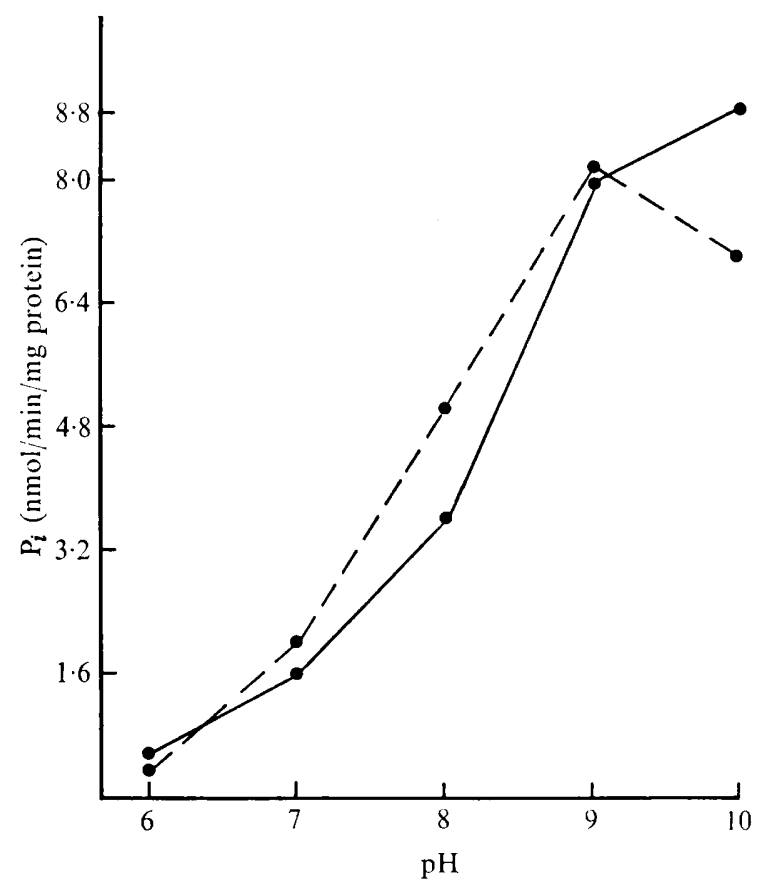

Fig. I. $\mathrm{Mg}^{++}$ATPase activity of isolated mitochondria of $B$-off wild type $(\bullet-\bullet)$ and $B$-on mutant (- - $)$ strains.

\section{Growth on glucose and ethanol}

The growth of the $B$-on strain is much less than that of the $B$-off strain on both $2 \%$ glucose and $2 \%$ ethanol. Growth on ethanol is interesting, because it is a mitochondrial energy source unlike glucose, which is both a cytoplasmic and mitochondrial energy source. The growth yield experiments showed that the mutant made about $3.4 \mathrm{~mol} \mathrm{ATP} / \mathrm{mol}$ glucose, and this indicated some in vivo mitochondrial energy conservation. It was therefore not surprising that the mutant grew on ethanol. The wild type achieved a greater yield on glucose than on ethanol (Fig. 2). The mutant, however, while growing considerably more slowly on ethanol than on glucose, had approximately equal final yield on both substrates. Whether this indicates a general uncoupling in the mutant cell, not localized to the mitochondria in vivo, remains to be seen.

\section{Effect of temperature on growth}

The effect of temperature on growth of the $B$-on mutants was interesting. Comparison of growth at $20{ }^{\circ} \mathrm{C}, 30^{\circ} \mathrm{C}$, and $37^{\circ} \mathrm{C}$, as determined by colony diameter at 6 days on minimal medium, revealed (Fig. 3) growth of the mutant to be more temperature-dependent than that of the wild strain in the range 20 to $30^{\circ} \mathrm{C}$. The mutant exhibited a $Q_{10}$ of 2 , compared with $\mathrm{I} \cdot 3$ for the wild type. At $6{ }^{\circ} \mathrm{C}$, the wild type grew extensively though slowly, and the mutant showed no growth. Therefore, the rate-limiting step for growth of the mutant strain differed from that of the wild type. This critical step might well coincide with some component of the cell's energy-conserving system. 


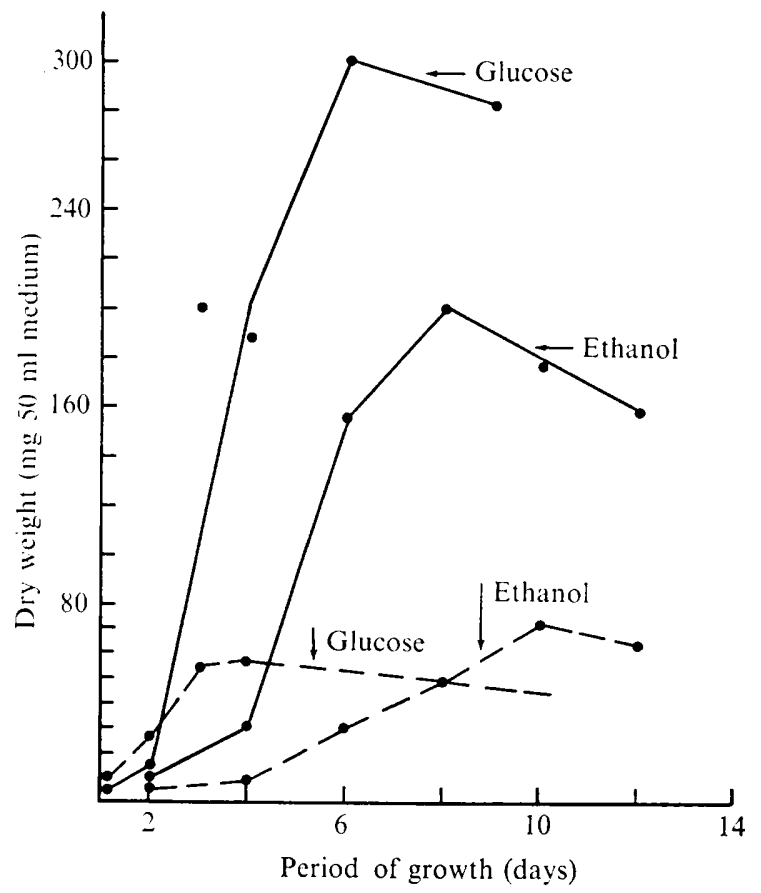

Fig. 2. Comparative growth of $B$-off wild type ( $2 \%$ glucose and $2 \%$ ethanol.

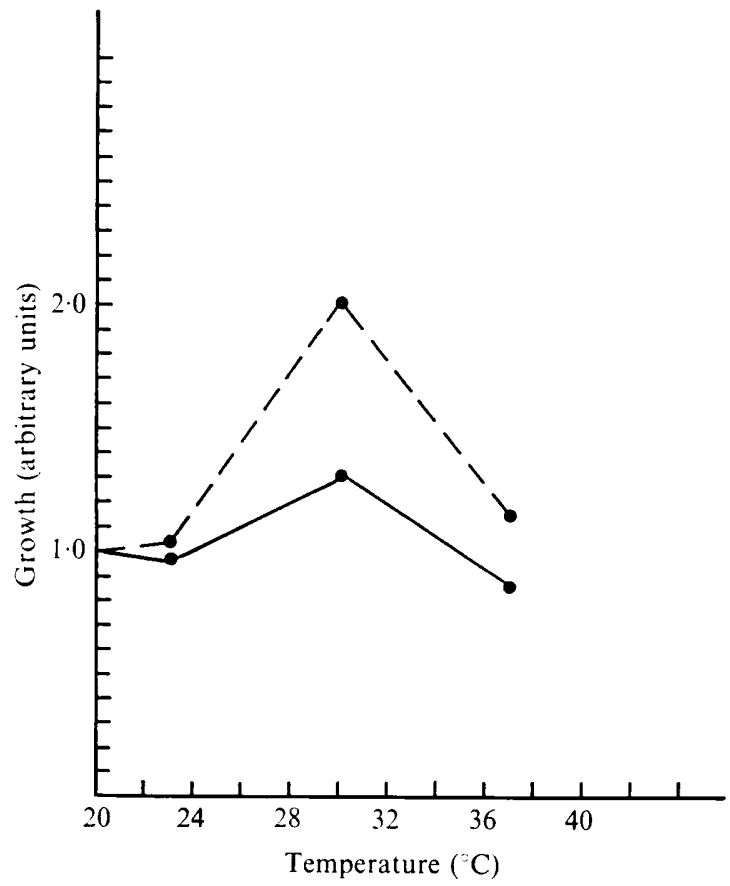

Fig. 3. Growth of $B$-off wild type (- $-\bullet)$ and $B$-on mutant (30 and $37^{\circ} \mathrm{C}$, expressed in arbitrary units with growth at $20^{\circ} \mathrm{C}$ taken as $1 \cdot 0$. 

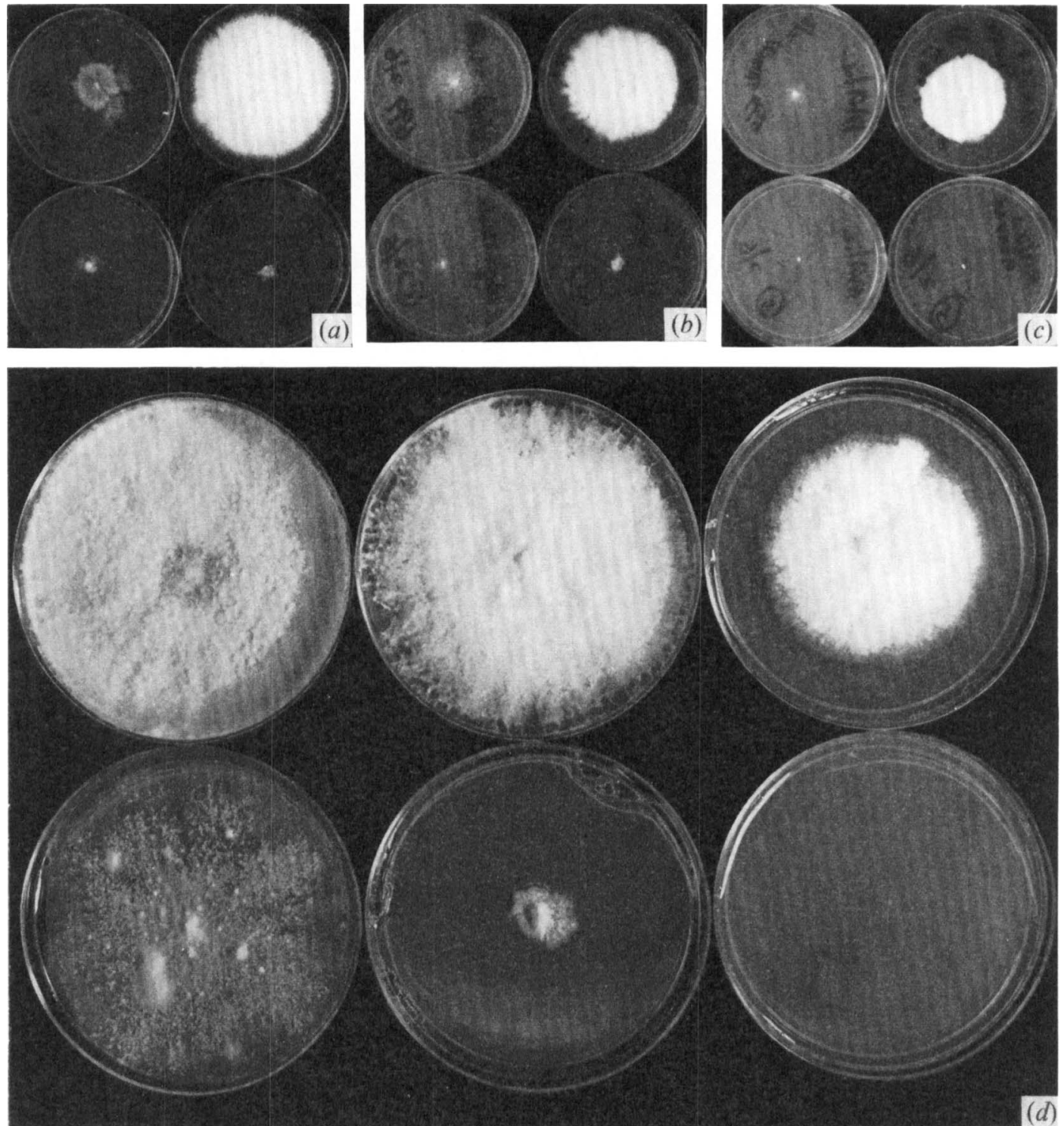

Fig. 4. Effects of pyruvate and Krebs-cycle intermediates on growth of $B$-off wild-type and $B$-on mutant strains of Schizophyllum. The wild strain is at the top of each set of photographs and the mutant at the bottom. (a) Pyruvate, $(b) \alpha$-ketogluterate, $(c)$ malate; in each set, $2 \%$ intermediary metabolite is at the left and $2 \%$ metabolite $+2 \%$ glucose at the right. $(d)$ Citrate at concentrations of $0,0.4$, and $0.8 \%$, from left to right respectively, plus $2 \%$ glucose.

\section{Preferential inhibition of the growth of the B-on mutant by Krebs cycle intermediates}

In the presence of glucose at a concentration of $2 \%$, malate and $\alpha$-ketoglutarate at the same concentration are almost completely inhibitory to the $B$-on mutant, whereas vigorous growth occurs with the $B$-off wild type. Pyruvate is also almost completely inhibitory to the mutant but with little effect on the wild type. Williamson (1965) demonstrated the inhibition of glycolysis (via inhibition of certain glycolytic enzymes, especially phosphofructokinase) in rat heart cells by citrate, the concentration of which was raised by intermediates 
of the Krebs cycle. This suggested that the pyruvate, malate, and $\alpha$-ketoglutarate were blocking glycolysis by raising the citrate level, with a greater effect on the growth of the mutant due to a possibly abnormal dependency on glycolysis. Citrate should thus have a greater effect on the growth of the mutant than on the wild type, and this was indeed the case. Citrate, at concentrations of 8 to $\mathrm{I} 2 \mathrm{~g} / \mathrm{l}$ and in the presence of $2 \%$ glucose at $30{ }^{\circ} \mathrm{C}$, permitted no growth of the mutant while vigorous growth occurred in the wild-type strain (Fig. 4).

\section{Effect of the oxidative phosphorylation inhibitor DCCD}

$\mathrm{N}, \mathrm{N}$-dicyclohexylcarbodiimide (DCCD) is a compound thought to inhibit phosphorylation and thereby inhibit respiration in coupled systems (Kovac, Galeatti \& Hess, I968). In both growth and respiration, however, the $B$-on mutant seems more sensitive to DCCD than the $B$-off wild type. DCCD at a concentration of $3 \times 10^{-4} \mathrm{M}$ inhibits growth of the mutant completely on minimal medium while allowing vigorous growth of wild type.

Respiration was measured in a Clark-type oxygen electrode at $30^{\circ} \mathrm{C}$ in minimal medium with $0 . \mathrm{I} \%$ glucose. DCCD at a concentration of $\mathrm{I} \cdot 24 \times \mathrm{IO}^{-4} \mathrm{M}$ inhibited respiration of the wild-type $27 \%$ and of the mutant $38 \%$. Although these values, each the average of 9 determinations, were significantly different at the $5 \%$ level ( $\mathrm{T}$ test), the important point was the sensitivity of the mutant. The coupling mechanism in the mutant thus seemed quite sensitive to DCCD, even though it was evidently operating at low efficiency. The low efficiency may have been due to a malfunction in a system operating after the initial events of coupling.

\section{DISCUSSION}

In Schizophyllum, the B-sequence, activated by either a mutant- $B$ gene or interacting wild-type $B$ genes, leads to a very inefficient metabolic system. The present studies with the $B$-on mutant demonstrated that mitochondria of normal efficiency but with reduced respiratory response to ADP (Hoffman \& Raper, 1972) could be isolated from a system that had about $9 \%$ the efficiency of the wild type.

Various lesions in a number of organisms have been found to disrupt oxidative phosphorylation with quite significant effect (Griffiths, Avner, Lancashire \& Turner, 1972). In Schizophyllum, an uncoupling of energy metabolism leading to a ninefold decrease in efficiency may be due simply to alteration in respiratory control of the mitochondria. Whether the reduction in respiratory control, however, is due to impairment of adenine nucleotide translocation (as in $\mathrm{OP}_{1}$ of yeast: Kolarov, Subik \& Kovac, 1972) or to lowered intramitochondrial concentration of high energy nucleotides (as in loosely coupled brown fat mitochondria: Flatmark \& Pedersen, 1973) remains an open question. Mitochondria isolated from skeletal muscle of a human subject with severe hypermetabolism of nonthyroid origin almost completely lack respiratory control, with somewhat reduced $\mathrm{P} / \mathrm{O}$ ratios (I.57/2.84) (Ernster \& Luft, I963). The nature of the lesion in the hypermetabolic human, which seems similar to that of Schizophyllum, is unresolved. The possibility of an endogenous uncoupler cannot be ruled out in Schizophyllum.

That growth and respiration in the $B$-on mutant were sensitive to DCCD indicated the presence of an active coupling system. This agreed with the finding in the mutant of a seemingly normal mitochondrial ATPase, the terminal enzyme in the coupling process. There is thus still the possibility that ATP is made normally and is broken down, e.g. by a cytoplasmic ATPase. The fact that the mutant had a yield on ethanol seemingly as good as on glucose, although the rate of growth was much slower on ethanol, may indicate a general uncoupling. This could be accomplished by an extramitochondrial ATPase that 
does not release $\mathbf{P}_{i}$. The greatly increased sensitivity of the growth of the mutant to Krebs cycle intermediates, however, may indicate a lesion localized in the mitochondria and a substantial dependency on glycolysis.

The unique feature of the impairment of energy conservation described here for Schizophyllum was its occurrence in the normal course of development of this organism. The $B$-on mutant examined here is constitutive for the B-sequence, a phase of development that normally occurs in heterokaryons heterozygous for $B$ incompatibility wild-type genes. The mutant, however, is genetically homogeneous and is the more favourable material for quantitative work. The $B$-on mutant and the $B$-on heterokaryon are phenotypically indistinguishable, and in both the B-sequence of development is fixed. In a normal mating between strains heterozygous for $A$ incompatibility genes as well as for $B$ incompatibility genes, B-sequence activity is transitory and precedes A-sequence development. A-and B-sequences constitute the entire process of sexual development and lead to fruiting and the completion of the life cycle.

This work was supported by National Science Foundation Grant GB-3I44I and U.S. Atomic Energy Commission Contract No. AT (I I-I) 3223. We are grateful for the excellent technical assistance of F. Schaefer and E. Diala.

\section{REFERENCES}

AMEs, B. (1966). Assay of inorganic phosphate, total phosphate and phosphatases. In Methods in Enzymology vol. 8, pp. I1 5-11 8. Edited by E. F. Neufeld and V. Ginsburg. New York: Academic Press.

BAUChOP, T. \& ElsDEN, S. R. (I960). The growth of micro-organisms in relation to their energy supply. Journal of General Microbiology 23, 457-469.

ERNSTER, L. \& LUFT, R. (I963). Further studies on a population of human skeletal muscle mitochondria lacking respiratory control. Experimental Cell Research 32, 26-35.

Flatmark, T. \& Pedersen, J. (1973). Studies on the energy state of isolated brown adipose tissue mitochondria. Effect of adenine nucleotides and oligomycin on the generation and dissipation of the "energy potential'. Biochimica et biophysica acta 292, 64-72.

Griffiths, D., AvNER, P., LanCashire, W. \& TURNER, J. (I 972). Studies of energy-linked reactions: isolation and properties of mitochondrial oligomycin-resistant, trialkyl tin resistant and uncoupler resistant mutants of yeast. In Biochemistry and Biophysics of Mitochondrial Membranes. Edited by G. Azzone, E. Carafoli, N. Siliprandi and E. Quagliarielb. New York: Academic Press.

Hoffman, R. M. \& RAPER, J. R. (197I). Genetic restriction of energy conservation in Schizophyllum. Science, New York 171, 418-419.

HOFFMAN, R. M. \& RAPER, J. R. (1972). Lowered respiratory response to ADP of mitochondria isolated from mutant-B strain of Schizophyllum commune. Journal of Bacteriology IIo, 780-781.

Hutner, S. H., Provasoli, L., Schatz, A. \& Haskins, C. P. (I950). Some approaches to the study of the role of metals in the metabolism of microorganisms. Proceedings of the American Philosophical Society 94, $152-170$.

Kolarov, J., SubiK, J. \& KovaC, L. (1972). Oxidative phosphorylation in yeast. IX. Modification of the mitochondrial adenine nucleotide translocation system in the oxidative phosphorylation deficient $\mathrm{OP}_{1}$. Biochimica et biophysica acta 267, 465-478.

Kovac, L., GaleatTI, T. \& Hess, B. (I968). Oligomycin-like inhibition of yeast respiration by $N, N^{\prime}-$ dicyclohexylcarbodiimide and the nature of energy coupling in intact yeast cells. Biochimica et biophysica acta 153, 715-717.

Miles, P. G., LunD, H. \& RAPER, J. R. (1956). The identification of indigo as a pigment produced by a mutant culture of Schizophyllum commune. Archives of Biochemistry and Biophysics 62, 1-5.

Nielsen, S. \& Lehninger, A. (1955). Phosphorylation coupled to the oxidation of ferrocytochrome C. Journal of Biological Chemistry 215, 555-570.

Ohnishi, T., KaWAGuchi, K. \& Hagihara, B. (1966). Preparation and some properties of yeast mitochondria. Journal of Biological Chemistry 24I, 1797-1806. 
RAPER, J. R. (1966). Genetics of Sexuality in Higher Fungi. New York: Ronald Press.

RAPER, C. A. \& RAPER, J. R. (1973). Mutational analysis of a regulatory gene for morphogenesis in Schizophyllum. Proceedings of the National Academy of Sciences of the United States of America 70, 1427-1431.

Schatz, G., Penefsky, H. \& RACKer, E. (1967). Partial resolution of the enzymes catalyzing oxidative phosphorylation. XIV. Interaction of purified mitochondrial adenosine triphosphatase from baker's yeast with submitochondrial particles from beef heart. Journal of Biological Chemistry 242, 2552-2560.

STOUTHAMer, A. H. (1969). Determination and significance of molar growth yields. In Methods in Microbiology, vol. I, pp. 629-663. Edited by J. R. Norris and D. W. Ribbons. London: Academic Press.

WANG, C.-S. \& RAPER, J. R. (1969). Protein specificity and sexual morphogenesis in Schizophyllum commune. Journal of Bacteriology 99, $29 \mathrm{I}-297$.

Williamson, J. R. (1965). Glycolytic control mechanisms. I. Inhibition of glycolysis by acetate and pyruvate in the isolated perfused rat heart. Journal of Biological Chemistry 240, 2308-2321. 